\title{
Histórias-míticas e construção da pessoa: ambiguidade dos corpos e juventude indígena em um contexto de transformações
}

\author{
Mythical stories and the construction of the individual: ambiguity \\ of the bodies and indigenous youth in a context of transformation
}

${ }^{1}$ Instituto Leônidas e M aria Deane, Fundação O swaldo

Cruz. Rua Terezina 476,

Adrianólopis. 69057-070

Manaus AM. maximiliano@

amazonia.fiocruz.br

${ }^{2}$ Insituto Fernandes

Figueira, Fundação Oswaldo

Cruz
Abstract Representations about youth vary historically and culturally. In the U pper Rio N egro, there are indigenous groups with over three centuries of contact with the non-indigenous world. In recent years, male initiation rites were suppressed and formal schooling was introduced. These events led to a redefinition of significance in forms of representation at different stages of life. This work sought to understand the construction of the Indian representation of youth; how they correlate with the other life cycle phases and how they contribute to configuring structured social practices in this social group. Several mythical stories dealing with intergenerational relationships have been reviewed; these were correlated with significant stages of life, with other local narratives, and with data gathered from direct observation. The study concludes that the representations about youth have been configured by the social roles of the initiating/initiated, in a currently contradictory fashion, under a ge neric and lengthy student phase, deprived of its own sociological markers, prolonging the threshold condition of this phase of life.

Key words South American Indians, Youth, Cultural change
Resumo As representações sobre a juventude variam histórica e culturalmente. No Alto Rio Negro, vivem grupos indígenas com mais de três sé culos de contato com o mundo não-indígena. N os últimos anos, os rituais de iniciação masculina foram suprimidos e houve a introdução da escola formal. Estes acontecimentos geraram ressignificaçoes nas formas de representar as diferentes fases da vida. N este trabalho objetivou-se compreender a construção das representações sobre a juventude indígena; como elas se correlacionam com as demais fases do ciclo vital e como contribuem para configurar práticas sociais estruturadas em torno deste grupo social. Analisaram-se diversas histórias-míticas que tratam das relações intergeracionais; estas foram correlacionadas com os termos designativos das diversas da vida, com as outras narrativas nativase com dados obtidos a partir da observação participante. 0 estudo conclui que as representações sobre juventude são configuradas pelos papeis sociais de iniciandos/iniciados, fundidosna atualidade, demodo contraditório, numa categoria genérica e prolongada de estudante, desprovida de estatuto sociológico próprio, alongando a condição liminar desta fase da vida.

Palavras-chave Índios sul-americanos, Juventude, Mudança cultural 


\section{Introdução}

As formas através das quais são categorizadas as diferentes fases da vida variam histórica e culturalmente ${ }^{1,2}$, pois, como adverte Bourdieu ${ }^{3}$ a idade é um dado biológico socialmente manipulado e manipulável. Um aspecto bem demarcado na literatura é que o surgimento da escola formal, entreos séculos XVII eXVIII naEuropa, influenciou deforma marcante a configuração das fases da vida no ocidente. Este evento teria tanto re configurado as representações ocidentais a respeito da infância ${ }^{4}$, como criado condições de possibilidade para 0 alongamento, ou mesmo para o surgimento, de uma categoria intermediária entre esta fase inicial e a vida adulta, chamada por vezes de juventude?.

No Alto Rio N egro, noroeste amazônico, habitam cerca de 30 mil indígenas ${ }^{5}$, distribuídos ao longo de diversos cursos d'água. Junto ao rio U aupés e afluentes habitam diferentes grupos da famílialinguística Tukano Oriental (Tukano, Dessano, Uanano, Bará, dentre outros), os Tariano, da família Aruaquee os H upda, da família M aku. Para os meninos, a passagem da infância para idade adulta dava-se pela iniciação ritual no culto masculino das flautas sagradas, interditado às mulheres ${ }^{6}$. Tal rito está em desuso em diversas áreas do U aupés brasileiro, associando-se, pelo menos em parte, à intolerância dos missionários salesianos ${ }^{7}$, queali introduziram, a partir de 1914, internatos escolares em moldes europeus.

Os grupos Tukano O riental e os Tariano são unidades exogâmicas, patrilineares e patrilocais ${ }^{8}$. Cada unidade é subdividida em grupos consanguíneos (os sibs), nomeados e hierarquizados de acordo com a ordem de nascimento dos ancestrais míticos fundadores. Cada assentamento deveria idealmente congregar homens (e seus fiIhos e filhas) de um mesmo sib e suas esposas advindas de outras unidades exogâmicas, vindas de outras locais?.

lauaretê, populosa localidade indígena multiétnica, localiza-seàs margens do U aupés. Lá residem indígenas falantes, em sua maioria, da língua Tukano e do Português, pertencentes a diferentes unidades exogâmicas. Em 2007 sua população era estimada em 2.779 pessoas. Credita-se o crescimento desta localidade à desativação, em 1986, do internato salesiano que ali funcionava desde 1930. Com seu fechamento, famílias inteiras passaram a migrar para lauaretê buscando dar continuidade à escolarização dos filhos ${ }^{10}$. lauaretê possui algumas ruas acimentadas, três escolas, um hospital, eletrificação, telefonia, agên- cia dos correios e acesso a internet, em um pelotão do Exército Brasileiro.

lauaretê encontra-se dividida em dez vilas. Há vilas tradicionais e outras novas. As primeiras se associam a antigas malocas de grupos Tariano, que lá residiam antes da chegada dos missionários salesianos, no início do século XX; as segundas se formaram posteriormente, com a vinda de indígenas de diferentes locais. Cada vila se organiza de forma independente, buscando manter seus ideais de autonomia e independência em relação às outras. Cada uma delas possui suas lideranças, seu agente de saúde, seu centro comunitário, sua capela, seu campo de futebol, e seus times esportivos, compostos por jovens.

0 acesso à terra cultivável, aos locais depesca mais piscosos, bem como aos cargos políticos de prestígio, tende a ser prerrogativa dos tarianos das vilas tradicionais. Tais questões evidenciam tanto a importância que o pertencimento a determinado sib possui no contexto local, como a relevância das bases sócio-cosmológicas na aconcoragem da compreensão da realidade e na orientação de práticas sociais por parte dos moradores de lauaretê.

Sendo lauaretêum pólo de atração populacional, a regra de residência patrilocal não está plenamenteem operação. M esmo no interior decada vila não se viveexclusivamentecom parentes. Localmenteos laços estabelecidos pela corresidência mediam em larga medida as estratégias para manutenção da coesão social no interior de cada vila.

Estratégias como a realização de festas, feiras, arraiais e outras situações similares nas quais se faz uso de bebidas alcoólicas são recorrentemente realizadas, sendo mecanismo para reforçar a solidariedade entre os corresidentes, bem como para demarcar as diferenças em relação aos moradores de outras vilas. Por outro lado, estas mesmas situações de consumo de álcool são culturalmente consideradas momentos propícios para explicitação de tensões e diferenças ${ }^{11}$.

Em Iauaretê, uma afirmação corrente é que os jovens bebem cada vez mais cedo, de modo mais frequente e violento, e que haveria dificuldades coletivas em se lidar com este comportamento. Uma pergunta inicial seria: em lauaretê, quando se fala dos jovens, sobre quem se está falando? Bourdieu ${ }^{3}$ alerta que em cada contexto cultural ehistórico, dinâmicas sociais complexas interagem para configurar as formas através das quais se real iza o recorte entre as diferentes gerações. Assim, para compreender, neste contexto sócio-cultural, a construção das representações sobre juventude; como elas se correlacionam 
com as demais fases do ciclo vital e como contribuem para configurar práticas sociais estruturadas em torno deste grupo, objetivos deste trabalho, teve-se que buscar referenciais teóricos que pudessem dar sentido às especificidades indígenas em geral, e rionegrinas em particular.

Inicialmente partiu-se do reconhecimento de que a transformação pela qual Iauaretê está passando vem sendo necessariamente adaptada ao esquema cultural existente ${ }^{12}$. Transformações, como a introdução da escola formal, e construções de sentido em torno delas se dão a partir de instituições, estruturas e lógicas próprias e pré existentes. 0 segundo ponto é que no contexto ameríndio os rituais de iniciação têm uma importância estrutural nas formas através das quais se configuram as diferentes fases da vida'; o iniciando encontrar-se-ia em uma fase liminar, escapando às classificações sociológicas, sendo marcado pela ambiguidade ${ }^{13}$. 0 ritual o encaminharia para um status definido epleno. Entendese que estes rituais de forma recorrente incidiam sobre os corpos dos iniciandos, através de diferentes formas de flagelo e modificações corporais $^{14}$. Tal processo ritual deve ser compreendido levando-se em consideração que no contexto indígena sul-americano, a fabricação, decoração, transformação e destruição dos corpos são temas em torno dos quais giram as mitologias (...) e ritos e que há a centralidade dos corpos nos processos de construção da pessoa ${ }^{15}$.

Em síntese, partiu-se do entendimento inicial de que as representações sobre a juventude e as demais fases do ciclo vital seriam produtos da interface entre as bases sócio-cosmológicas que ordenam o viver indígena e as transformações históricas vividas ao longo dos anos. Levou-se em consideração a importância estrutural dos ritos de iniciação, que mediariam a construção da pessoa, enquanto ser social pleno, através de modificações corporais, e a necessidade de re ordenar o universo simbólico com entrada destes rituais em desuso e com a introdução da escola formal, buscando sempre um diálogo com a literatura etnográfica rionegrina clássica ${ }^{6,8,9,16,17}$ e contemporânea7,10,18,19.

\section{Metodologia}

Foi realizada uma pesquisa etnográfica em I auaretê, com seis meses de duração. Em campo, buscou-se estabelecer relações dialógicas com diferentes grupos. Um destes foi um grupo de quatro idosos, reconhecidos localmente como co- nhecedores das histórias e mitos indígenas. Eles coordenavam uma atividade extraclasse, ministrando aulas sobre cultura para estudantes da escola local. Tão logo o primeiro autor deste trabalho apresentou-se e Ihes explicou o interesse em compreender sua cultura, eles recomendaram-no assistir suas aulas. Com o passar do tempo estabeleceu-se um relação empática entre o pesquisador e os idosos, de forma que quando os alunos iam embora, começava uma descontraída seção de conversa, na qual se abordavam assuntos diversos, e se narravam histórias.

Parte dessas histórias tinha em comum o fato dos personagens não serem os ancestrais da humanidade, como nos mitos, mas serem os próprios homens, interagindo num mundo liminar com o mítico, assemelhando-se às histórias-míticas, identificadas por $\mathrm{H} \mathrm{ill}{ }^{20}$ entre grupos indígenas sul-americanos. Segundo este autor, através deste tipo específico de produção, os nativos buscariam atribuir sentidos aos eventos que ocorreram a partir do contato interétnico, reconstruindo, a partir dos mitos, uma interpretação das transformações históricas. N estas ocasiões coletou-se um conjunto de quatorze histórias-míticas, que foram interrompidas quando se percebeu que se havia chegado a um ponto de saturação ${ }^{21}$.

Aos narradores, solicitou-se que identificassem as etapas de vida dos diferentes personagens, através de termos em Tukano, e que os traduzissem para o Português. Assim, o acervo pôde ser dividido em histórias de wi'magi/wi'mago (menino/menina; criança), de ma'mî/numió (jovem, moço/moça), e de biki/bikió (velho/velha; idoso/idosa). Selecionaram-se para análise histórias-míticas nas quais foi possível encontrar aproximações entre seus enredos e o contexto social contemporâneo delauaretê, dando-sepreferência àquelas cujos próprios narradores fizeram esta associação. As demais histórias, utilizadas de forma secundária, foram úteis na medida em que serviram para evidenciar a importância e a recorrência dos temas destacados para uma investigação em profundidade, sendo uma estratégia utilizada para minimizar os riscos de centralizar as análises em aspectos fortuitos e idiossincrásicos de determinadas histórias.

A título de pré-análise, se buscou evidenciar nas histórias os diferentes personagens, as formas deinteração entreeles, a sequência dos acontecimentos, o cenário nos quais transcorreriam ${ }^{22}$. A seguir procedeu-se análise através de três estratégias complementares. A primeira partiu do reconhecimento que as palavras na língua nativa possuem ideias e conceitos implícitos, passíveis 
de serem negligenciados no processo de tradução ${ }^{7}$. Com um informante-chave, investigou-se os diferentes sentidos das palavras utilizadas, na língua nativa, para demarcar as etapas do ciclo vital, cotejando com dados disponíveis na literatura ${ }^{23}$, e com o uso cotidiano destas expressões, objetivando construir associações entre estas informações e as formas através das quais os personagens eram representados nas histórias. A segunda estratégia consistiu em cotejar as histórias-míticas a mitos rionegrinos, buscando entre eles aproximações, distanciamentos, inversões de sentidos e outras possíveis correspondências ${ }^{24}$. Por fim, utilizaram-se dados obtidos a partir de observação e diálogos informais, no intuito de caracterizar as aproximações feitas pelos narradores entre as histórias e o contexto contemporâneo delauaretê, operando como estratégia para correlacionar as representações e as práticas sociais relacionadas à juventude.

\section{Histórias de wi'magi/wi'mago}

Estas histórias tinham como cenário a roça demandioca; abordavam tentativas detransmissão de ensinamentos entre mãe e criança, ligadas ao processo de construção de corpos, tais como regras alimentares ou, como no caso abaixo, de asseio corporal ${ }^{15}$.

U ma criança não queria acompanhar sua mãe na ida para roça, para ficar brincando na maloca, alegando que lá havia muitas cabas (Polystes sp). Com a insistência da mãe a criança acabou indo, maschegando lá foi picada por esteinseto. Ao ocorrer este fato a mãe dirigiu-se a criança e comentou: "Está vendo? I sso acontece porque você não toma banho direito pela manhã!".

Para compreensão da história acima, demarca-se que localmente, estimula-se a criança a tomar banho cedo do dia, na água gelada do rio. 0 não cumprimento desta prescrição tornaria as pessoas fracas, moles e preguiçosas. A ironia da história acima parece estar relacionada à habilidade da mãe em desmascarar a preguiça da criança, ea inabilidade desta última em escondêla. Durante a narração de outra história foi motivo de riso a mordida que levou uma criança ao não conseguir comer um besouro conforme a orientação de sua mãe. Assim, um ponto recorrente nestas histórias é a explicitação da inabilidade/ desconhecimento infantil.

Wi'magi/wi'mago são palavras compostas pelo verbo wi'má, "estar de pouca idade" 23 , e pe los sufixos, masculino ( $g$ t) ou feminino ( $g 0$ ). Jáo verbo wimá significa efetuar a primeira etapa da torrefação da farinha ${ }^{23}$. Assim, a criança, enquanto neófito seria um ser que está em processamento. Sua inabilidade correlaciona-se com sua incompletude. Neste contexto o processo de construção da pessoa não se restringe ao mundo uterino e adentra no ambiente extraútero, mediado pela aquisição de habilidades sociais, que modelam e são modeladas pelos corpos.

A criança seria de certa forma um ser pré social. Sob uma perspectiva masculina, seria evidência desta condição sua maior associação à roça e ao universo das mulheres, e não à maloca e ao universo masculino, díades que demarcam no contexto rionegrino o campo da natureza e da cultura ${ }^{8}$. Ritualisticamente, esta condição era explicitada pela exclusão das crianças e das mulheres dos ritos associados ao culto das flautas sagradas. A penas os já iniciados, já apresentados aos saberes esotéricos de seu sib, cujos corpos foram singularizados pelo açoitamento ritual e pelo uso de enfeites específicos para seus grupos, participavam ativamente dessas atividades ${ }^{6}$. E é este corpo, diferenciadamente humano, culturalmente construído, quea criança ainda não possui plenamente, eque demarca sua incompletude.

\section{Histórias de ma'mî/numió}

Aprendizado/prescrições/desobediência

Este conjunto de histórias faz alusão ao ritual de iniciação masculina, relacionado ao complexo mítico-ritual do Jurupari ${ }^{6}$. Numa das histórias coletada, o narrador explicita que este era o momento para se aprender aquilo que os antigos falavam-contavam-faziam. No processo narrativo da história abaixo, o narrador fez uma complexa mediação entre ela, o mito do Jurupari e o contexto contemporâneo de lauaretê.

Numa maloca havia um jovem que estava na "preparação para maturidade", e uma jovem que estava no isolamento da primeira menstruação. Para o jovem havia várias comidas proibi das, como o japurá (Erisma japura). As mulheressaíram para roça. Seu pai e outros homens ao saírem para pescar, chamaram o jovem. Este viu na situação uma oportunidade para comer o japurá escondido. Disse ao pai que fosse à frente. Esperou todos saírem e retornou para maloca. A jovem reclusa observava tudo por uma fresta. Os homens voltaram da pescaria. 0 jovem usou de uma série de estratégias para que não descobrissem que ele havia comido japurá, mas a jovem acabou contando. Ele saiu para evitar a reprimenda do pai. Depois voltou e foi discutir com a jovem. Ele a chamou de "fofoqueira". Aproximou-se do cercado onde a jovem 
estava e colocou seu ol ho numa fresta. A jovem cuspiu-Ihe caldo de pimenta no olho.

O narrador, como preâmbulo, informou que Jurupari seria tipo um professor de três jovens ou alunos. Ele era bastante exigente, prescrevendoIhes uma série de restrições alimentares. Ao término da história, informou que no tempo ancestral, os jovens que estavam sob os cuidados de Jurupari também descumpriram restrições alimentares, eigualmentetentaram acobertar seu deslize. Mas ele puniu os jovens, engolindo-os. Seus pais vingaram-se do Jurupari, matando-o. Explica que no mito, as restrições eram muito maiores que na situação tratada na história. Ainda sim, os jovens não as teriam seguido. Concluiu, articulando a ancestralidade ao mundo atual: E hoje é do mesmo jeito!.

Nos rituais de iniciação, os corpos infantis eram singularizados, ao serem pintados e adornados com enfeites cerimoniais, inserindo os iniciandos no mundo dos adultos de seu grupo ${ }^{6}$. M a'mît compartilha seu radical com ma'mâtihi, enfeitar-seecom ma'má, quesignifica novato num determinado lugar. Nu'mió associa-se a nu'miá, torna-se enfeitado, ou tornar-se moça.

Há um ponto convergentenas diferentes versões do mito do Jurupari. Após sua morte uma série de desgraças surgiu no mundo ${ }^{25,26}$. As flautas usadas na iniciação masculina, que formavam o corpo de Jurupari, foram apropriadas pelas mulheres. 0 destino das flautas era pertencer aos homens, mas isso quase não se deu, devido à falha de um iniciando que deveria acordar cedo para banhar-se e achá-las na beira do rio. Como ele acordou tarde, suas irmãs acharam as flautas. Então as mulheres se masculinizaram e inverteu-se a divisão sexual do trabalho, que só foi desfeita após a captura das jovens e sua expulsão do mundo habitado pelosindígenas. Tanto no mito, quanto na história, havia restrições alimentares aos jovens, que ao serem desrespeitadas trariam prejuízos.

Os mitos são as bases sobre as quais se assentam diversos rituais, que têm, entre suas funções, o reforço das normas sociais ${ }^{27}$. No ritual de iniciação masculino, antes praticado no Rio $\mathrm{Ne}$ gro, os corpos eram marcados pelo açoitamento ritual6; nesta situação, a sociedade imprimia sua marca no corpo do jovem, impedindo o esquecimento das normais sociais e proclamando seu pertencimento ao grupo ${ }^{14}$.

0 processo colonizatório introduziu a escola formal, que se associa a mudanças no modo de vida dos indígenas, como o cumprimento de horários fixos e avaliações formais de desempe- nho. Surge também a relação ma'mî/buêgí (estudante ou aluno), que, em parte, parece ter como referência a condição ma'mîtiniciando. Tais mudanças trazem consigo novas prescrições aos jovens indígenas. Estes deveriam evitar o consumo excessivo de bebidas alcoólicas e frequentar as festas com moderação. M as os jovens, só se pre ocupam com bebida, só querem saber de diversão, conforme relata uma mulher adulta. N o contexto atual, a tríade representacional aprendizado/ prescrições/desobediência permanece associada à ideia dejuventude.

Atual mente, compreende-se que desobediência não teria seu contraponto na rememoração promovida pelo ritual. Souza e Garnelo ${ }^{19}$ verificaram que os próprios jovens estabelecem uma valoração privilegiada aos'conselhos deantigamente', que eram oferecidos de forma ritualística; [ sem eles], 'a cabeça fica fechada e os conselhos não entram'. Para os autores, abolidos estes rituais não surgiram outras estratégias igualmente eficazes em reafirmar as normas sociais.

Ademais, o período escolar é mais extenso que o período de iniciação, retardando o casamento: com 15 ou 17 anos, já era para casar, disse um informante. Assim, prolonga-se o tempo da juventude, visto que para muitas pessoas o casamento demarcaria o fim desta fase.

0 término do período escolar não significa a entrada do jovem no mundo adulto. Desde wimá'gi/wima'go frequentam a escola, que valoriza a escolarização progressiva, para além daquela ofertada em lauaretê, como meio de acesso a empregos assalariados, que ali são escassos. A socialização escolar, diferentemente daquela que ocorria na iniciação tradicional, prolonga o período da juventude; édesprovida deessência ritual e esotérica; cria expectativas, muitas vezes inalcançáveis; e é direcionada para exterior, e não para o interior do grupo de parentesco.

\section{Ambiguidade/"malandragem"}

Outro conjunto de histórias aborda a capacidade dos jovens em dissimular e confundir os demais membros de seu grupo. Numa destas histórias, em uma longa viagem de canoa um jovem que comia escondido a carne moqueada que seu pai levava para presentear outro parente, convence que a mesma teria sido roubada por outra pessoa em alguma local no qual pararam. $\mathrm{N}$ a história abaixo, se apresenta de forma explícita esta representação do jovem que remete a ideias de ambiguidade e malandragem.

Todos os dias os homens e as mulheres de uma maloca saiam para cumprir seus afazeres. N esta 
situação, um rapaz que ficava sozinho com as crianças colocava uma máscara e pintava o corpo para assustá-las e comer a comida delas. Quando os pais voltavam, as crianças contavam o ocorrido. Algumas mulheres resolveram se esconder na maloca para descobrir o que acontecia. N este dia, o rapaz foi entrando na maloca todo enfeitado. Vendo aquele ser de aparência indefinida, as muIheres pensaram se tratar de um espírito da floresta. Sabendo que estes não suportam cheiro de pimenta começaram a queimar este condimento. 0 cheiro começou a entrar através de sua máscara. $N$ ão conseguindo retirá-la, o chei ro forte o fez cair no chão. As mulheres tiraram-Ihe a máscara, descobriram queera um dos rapazes da maloca, eacabaram com sua "farsa".

Nos mitos rionegrinos há uns seres chamados Diroá. Eles se caracterizam pela sua ambiguidade: eram pequenos e gostavam de brincadeiras como crianças, mas possuíam energia sexual e conhecimentos xamânicos. Diz-se que os Diroá são muito malandros, dada suas habilidades em dissimular ${ }^{26}$. Seus inimigos eram os yaî-mast (gente-onça). Em diversas ocasiões, valendo-se da aparência infantil, convidaram os filhos de seus inimigos para brincar, mas tratava-se de artimanha para matá-los. Valendo-se do mesmo subterfúgio, atraíam as jovens filhas de seus inimigos para locais distantes, para manterem relações sexuais com elas.

Comparando o rapaz da história aos Diroá, observa-se uma inversão simétrica da relação entre essência e aparência. 0 rapaz ao vestir-se como um outro ser, faz-se ver como poderoso. Os Diroá, com seus corpos infantis escondiam os poderes que tinham.

Durante o trabalho de campo, o pesquisador, que observava um conjunto de jovens dançando, chamou-os demeninos. Um idoso ali presente comentou, de forma irônica: É... são meninos que fazem meninos, alertando que as aparências enganam. Uma mulher adulta, informou que as crianças ao ficarem sozinhas com jovens podem imaginar que são como eles. Confundindose com os jovens, tomam caxiri, fumam, brigam e namoram, aprendendo suas malandragens.

Observa-se que o cerne da questão está na ambiguidade dos corpos e papeis juvenis, que se acirra no contexto de transformações enfrentado pela população delauaretê. Os jovens escolares podem aparentar serem crianças, mas detêm potencialidades (sexual, por exemplo) que estas não possuem. 0 uniformeescolar, que os distingue do velho, acentua esta ambiguidade, visto que crianças também os usam. Não há, como havia na época em que se praticava o ritual de iniciação, uma clara definição do fim da infância. Vê-se nessa ambiguidade uma espécie de malandragem, no qual os jovens escondem potencialidades de adultos, por trás de corpos infantis e de roupas de aluno.

\section{Contato com os "outros"}

Nesteterceiro conjunto de histórias, se aborda de forma recorrente a relação entre os jovens e o estabelecimento de contato com a alteridade. Há histórias que relatam o encontro de jovens com onças, com seres da floresta, com certo pajé que faz errar o caminho, e também com outros tipos de gente, como no caso abaixo.

Quatro jovens estavam procurando o buraco onde se escondia uma cobra. U m dos jovens subiu num buritizeiro (Mauritia flexuosa). A árvore voou e caiu no rio. Quatro filhas do gente peixe observaram que havia uma pessoa em cima do buritizeiro, e comentaram com seu pai. 0 gentepeixe não tinha filhos homens. Então disse às fiIhas: "Tragam-no para cá. Ele será nosso empregado". As filhas do gente peixe pediram para ele descer, mas ele não descia. Isso porque escutara o que o gente-peixefalara. Seduzido pelasjovens, acabou descendo. Passou a morar com a gente- peixe, trabalhando para eles, até que conseguiu fugir e voltar para sua maloca e contou tudo o que viu e aprendeu por lá.

$\mathrm{Na}$ história, o jovem se movimenta por outro mundo, fazendo contato com uma sociedade não humana; ficando implícito que no retorno ao seu grupo de parentes traria consigo novas aquisições culturais.

Observa-se aqui uma associação simbólica entre 0 jovem e o guerreiro. Esta afirmação se sustenta nos seguintes argumentos: tanto 0 jovem iniciado não casado quanto o guerreiro, tinham em comum o fato de estarem direcionados para os limites exteriores do grupo de parentesco; seja para o contato hostil, ou para a busca de mulheres ${ }^{16}$. Além disso, os jovens iniciados costumavam ser recrutados como guerreiros ${ }^{17}$.

Uma das motivações das guerras era a captura de crianças. As meninas poderiam se tornar esposas dos filhos dos raptores e os meninos poderiam ser incorporados ao grupo de raptores, na condição de servos ${ }^{28}$. Afirma-se que no contexto rionegrino, não se faziam guerras com afins verdadeiros e que o estabelecimento desses laços criava obrigações recíprocas de paz e proteção ${ }^{9}$.

$\mathrm{Na}$ história acima o sogro-peixe tinha 0 intento de transformar o jovem em empregado, servo de gente- peixe, ou seja, um tipo de gente- 
peixe. Está também explícita a conotação sexual da relação entreo jovem indígena eas jovenswa'îmasa. Assim, nesta história pode-seencontrar de forma implícita os elementos antes apontados, 0 perigo imanentedo contato com a alteridade, ea possibilidade de angariar vantagens, como obter esposas necessárias para a reprodução social e cultural.

Ao terminar de contar a história, o narrador fez uma articulação com o contexto atual de lauaretê, e em tom que mesclava lástima e crítica, afirmou: e aqui existem muitos jovens que esquecem dos pais, e ficam morando com o sogro. Esta colocação parece apontar para um entendimento que a quebra da regra de residência patrilocal impactaria de alguma forma no modo como os jovens são representados.

Em lauaretê, dada a convivência multiétnica, os afins moram logo ali, e não em outras localidades, ou outros mundos. Isso dispensa os jovens de procurar futuras parceiras em outros locais, como ocorre em muitos aldeamentos rionegrinos. Assim torna-se compreensível a associação comumente feita entre os jovens do sexo masculino e o envolvimentos dos mesmos em disputas, por vezes violentas, por namoradas. Ademais, destaca-se que o namoro, ao que tudo indica prática social nova entre os indígenas da região ${ }^{7}$, não significa aliança matrimonial em curto prazo, o que por sua vez amplia o tempo das disputas e da própria juventude.

Por outro lado, deve-se igualmente atentar para o fato de que no contexto ameríndio ficar com os afins significa também ficar como os afins, tornando-se como um deles ${ }^{29}$. Por exemplo, noutra história coletada, um homem acompanhou um conjunto demulheres numa viagem. Durante 0 trajeto até a residência das mesmas, elas iam se transformando em minhocas, flores, bichos; e o homem se transformava como elas. Finalmente chegando à terra das mulheres, todos se transformaram em um tipo de fruto. Lá residindo sob a forma de fruto o homem se esqueceu de todos seus parentes.

No contexto contemporâneo há também 0 contato mais próximo e constante com o mundo dos brancos, através da escola, da televisão e das viagens cada vez mais frequentes à cidade. Como ocorrido nas histórias apresentadas nesta seção, o jovem pode sair eretornar do mundo não indígena, trazendo novos saberes a serem apropriados pelo seu grupo de parentesco. M as também podem nele ficar, tornando-se como os brancos.

A associação com os brancos não é um elogio. Referindo-seaosjovens, uma dasinformantes idosas disse: Briga, assassinato, estupro, roubo. Tudo o que os brancos fazem, eles querem fazer aqui. Ela também sustentava que com o casamento, esta agressividade seria subjugada; considerava que ao casarem as pessoas não pensam mais em maldade, e passam a pensar como parentes. 0 estabelecimento de relações reais de afinidade disciplinaria e enquadraria o jovem no seu grupo de consanguíneos, guiando-o para o cumprimento das regras de sociais, demarcando 0 fim da juventude.

Histórias de bikitlbikió

$\mathrm{N}$ as histórias de błki/błktó, o personagem principal era um homem casado e com filhos. Recorrentemente no enredo das mesmas se evidenciava a representação do velho como al guém que deveria proteger os mais jovens de seu grupo. Em algumas histórias, contadas como piadas, 0 elemento cômico era justamente a incapacidade de certo velho em proteger os seus, em comparação a outros que executariam a contento esta tarefa. N outras, como na história abaixo, se destaca como um elemento distintivo desta fase da vida os conhecimentos que proporcionavam aos veIhos a capacidade de proteger seus parentes.

U m velho estava caçando com seu filho na floresta, utilizando cachorros. Os cães partiram em disparada atrás de uma cotia. M as a presa era um espírito da floresta, um wãtî. Filho e pai foram conferir; o primeiro à frente e 0 segundo atrás. 0 jovem acabou sendo capturado pelo wãtî, que exalava odores fétidos. 0 jovem tentou escapar esfaqueando o espírito da floresta, que acabou Ihe soltando. Exposto aos odores, ficou como morto. 0 velho utilizou-se de recursos xamânicos e o trouxe à vida.

Bikt significa vel ho, e se relaciona aos termos de parentesco de afinidade błkí/błkió, esposo/esposa ${ }^{23}$. Ser esposo (a) e ter filhos são condições necessárias para se entrar nesta fase. Por exemplo, em campo uma mulher de trinta anos, com dois filhos e emprego assalariado informou ser nu'mió. Segunda ela, não poderia ser błkió, porque não tinha marido.

N estahistória o jovem mostrou-seintempestivo e o velho cauteloso. 0 primeiro optou pelo embate corporal; o segundo pelo uso de poderes xamânicos, estabelecendo-se entre eles uma relação de protegido-protetor. Em lauaretê, diz-se que, através de seus conhecimentos xamânicos, os velhos podem proteger suas famílias, benzendo os 'netinhos' quando ficam doentes, ou abrindo a cabeça dos jovens para os conselhos. Os velhos, têm mais conhecimentos, porque ouvi- 
ram os mais velhos do que eles. Entretanto, estes mesmos conhecimentos deixam os velhos em suspeição, pois Ihes conferem a capacidade de fazer o mal: 0 velho amaldiçoou com fumaça de cigarro; - era a explicação recorrente em caso de adoecimento e/ou morte de al guém.

Há também uma associação entre velho/avô e o conhecimento dos antigos, algo que confere prestígio aos mais velhos. Porém, a posição hierárquica de cada seguimento é sempre relativa. Entre os U anano, Chernela ${ }^{9}$ identificou que os sibs são hierarquizados, em ordem decrescente, em grupos de netos, tios e avós, invertendo a relação demaior prestígio dos mais vel hos frente aos mais novos. Os estudos de Jackson ${ }^{8}$ entre os Bará oferecem uma chave explicativa para esta inversão. Analisando o mito de origem do grupo, a autora informa que os ancestrais emergiram sequencialmente de uma cobra-canoa, saindo para o mundo humano, a partir de diferentes partes do corpo do animal. Os que saíram da cabeça emergiram primeiro, dando origem aos sibs de maior prestígio, e assim sucessivamente. Porém, os ancestrais que saíam da cobra-canoa eram numerosos; então, os últimos a emergir (oriundos da cauda), já encontraram os netos dos que primei ro haviam desembarcado. Por esta razão, a hierarquia mítica da formação do parentesco situa os sibs de netos em plano mais privilegiado que os sibs dos avôs.

EntreosD essano, o sib de avôsétambém chamado de sib de kumua, xamãs-rezadores ${ }^{18}$. A fala de um septuagenário ilustra a permanência deste sistema classificatório; ele informou que outro homem mais jovem era seu avô; porém evitava chamá-lo assim, porque poderia subentender que o outro era cheio de veneno, de maldade.

Na vida cotidiana avô podeser simplesmente o pai do pai, um homem com mais idade, cujo filho tevedescendentes. Hugh-Jones ${ }^{16}$ informa que à medida que os homens vão envel hecendo eacumulando participações nos rituais masculinos, que marcam seus corpos, eles também se tornam mais experientes, ampliando seus conhecimentos e se aproximando mais do mundo de seus ancestrais.

0 avô, classificatório ou real, é, portanto, aquele que está mais próximo do espaço-tempo dos ancestrais. No caso dos sibs de avós, esta aproximação dar-se-ia pelo menor distanciamento que têm da cobra-canoa, da qual foram os últimos a sair. Já o outro tipo de avô (o pai do pai), com sua idade mais avançada, pode acumular múltiplas participações nos rituais masculinos, que the permitiram se reaproximar do mundo mítico. No contexto atual, no qual os rituais não são mais praticados, os velhos/avós, também estão mais próximos dos ancestrais, porque tiveram oportunidade de conviver com os antepassados, portanto conhecem melhor a tradição.

\section{Considerações finais}

Em lauaretêvive-seem um contexto de rápidase importantes transformações, que como se buscou evidenciar, impactam de forma decisiva na forma como se representa as diferentes fases da vida. Pode-se também demonstrar que é possível compreender essas novas configurações representacionais recorren do a elementos estruturais, como mitos e ritos, que fornecem a base de sustentação para essa ordenação (e desordenação) do mundo em termos simbólicos ${ }^{12}$.

Observou-se que as modificações corporais mediam o processo de construção da pessoa ${ }^{15}$, e consequentemente, a constituição representacional das fases do ciclo vital. A incompletude do corpo infantil e sua associação ao caráter pré social da criança, tem seu contraponto no corpo ritualmente transformado do jovem. Porém, a completude juvenil mostra-se relativa quando comparada à dos velhos, cujos corpos acumulam as marcas da participação nos rituais ao longo da vida, e a conhecimentos esotéricos, estando associados a termos de afinidade, que evidenciam sua capacidade plena de reprodução cultural e social do grupo.

A análise das histórias-míticas permitiu ratificar os pressupostos adotados, que para compreender as representações sobre a juventude contemporânea de lauaretê, far-se-ia necessário considerar a importância estrutural dos rituais deiniciação 1,13,14, mas também as ressignificações requeridas pela introdução da escola formal3,4.

Neste processo de ressignificação, as representações de etapas vida outrora separadas pel os rituais de iniciação, como a de iniciandos - que se relaciona a aprendizado/prescrições/desobediência, ambiguidade/"malandragem" - e a dos já iniciados - associados ao contato com os "outros" - fundem-se contraditoriamente numa categoria genérica de juventude. Esta, por sua vez, está associada à ideia de estudante ou aluno que parece não ter um estatuto sociológico próprio, no contexto investigado, fazendo com que um período longo da vida permaneça, de certa forma, no campo da liminaridade.

Estas recomposições representacionais pare- 
cem estar relacionadas à compreensão/imputação de práticas sociais pelos jovens indígenas contemporâneos. Estes são genericamenteapontados como pessoas que se envolvem, de modo recorrente, em brigas relacionadas a disputas por mulheres. Ora, o que esperar de alguém que é representado como estando numa fase da vida caracterizada pela desobediência, ambiguidadee pela busca de contatos com estranhos? A alternativa encontrada para o controle do comportamento disruptivo juvenil, é que deixem de ser jovens, casando-se e tendo filhos. Só assim sairiam desta situação liminar, potencialmente perigosa. Entretanto, as famílias não querem que os filhos casem enquanto são alunos.

Por fim, mas igualmente importante, é preciso atentar para o fato que nesta pesquisa as narrativas foram coletadas com pessoas mais vel has, que se reconhecem e são reconhecidos pelo conhecimento dos mitos e das histórias dos tempos antigos. Pessoas como eles têm certa prerrogativa não só para contar histórias, mas para reinterpretá-las a luz das modificações do contexto no qual se vive, e interpretar o contexto sob o prisma das histórias recontadas. H averia, até certo ponto, algo de hegemônico nas formulações destes narradores, o que confere importância às questões aqui apresentadas. Por outro lado, um saber supostamente hegemônico não énecessariamente único ou monolítico. É bem possível que se coletássemos histórias com mulheres idosas, ou com jovens, outras posições contra-hegemônicas emergiriam, o que poderia evidenciar distinções e/ou tensões entre gêneros e entre diferentes classes de idade, algo que pode ser um caminho promissor para investigações posteriores.

\section{Colaboradores}

M LP Souza participou de todas as etapas relacionadas à elaboração do artigo. SF D eslandes e L Garnelo participaram da redação e revisão crítica do texto. 


\section{Referências}

1. Mead M. Coming of age in Samoa. London: Haper Collins Press; 2001.

2. Amit-Talai V, Wulff $\mathrm{H}$. Youth cultures: a cross-cultural perspective. London: Routlege; 1995.

3. Bourdieu P. Questões de Sociologia. Rio de Janeiro: M arco Zero; 1983.

4. Aries P. História social da criança e da família. $2^{a}$ ed. Rio de Janeiro: Zahar; 1981.

5. Pagliaro H, Azevedo M M, Santos RV. Demografia dos povos indígenas no Brasil. Rio de Janeiro: Fiocruz; 2005.

6. Hugh-Jones S. The palm and the pleiades: Initiation and Cosmology in Northwest Amazonia. Cambridge: Cambridge University Press; 1979.

7. Lasmar C. De volta ao Lago de Leite: Gênero e Transformação no Alto Rio N egro. São Paulo: UNESP/ ISA; Rio de Janeiro: NUTI; 2006.

8. Jackson JE. The fish people: Linguistic Exomamy and Tukanoan Identity in N orthwest Amazon. Cambridge: Cambridge University Press; 1983.

9. Chernela JM. The Wanano Indians of the Brazilian Amazon: a sense of Space. Austin: University of Texas Press; 1993.

10. Andrello G. Cidade do índio: Transformações e Cotidiano em Iauaretê. São Paulo: UNESP/ISA; 2006.

11. Souza M LP, Garnelo L, Deslandes S. Modos de vida e modos de beber de jovens indígenas em um contexto de transformações. Cien Saude Colet. No prelo 2009.

12. Sahlins M. 0 "pessimismo sentimental" e a experiência etnográfica: porque a cultura não é um objeto em via de extinção (Parte I). M ana 1997; 3(1):41-73.

13. Turner $V$. Variations on the theme of liminarity. In: Moore SF, M yerhoff BG, editors. Secular ritual. Amesterdan: Van Gorcum; 1977. p. 36-52.

14. Clastres P. A sociedade contra o Estado. 2a Ed. Rio de Janeiro: Francisco Alves; 1974.

15. Seeger A, da Mata R, Viveiros de Castro E. A construção da pessoa nas sociedades indígenas brasileiras. Boletim do M useu Nacional 1979; 32: 2-19.

16. Hugh-Jones $C$. From the milk river: Spatial and temporal processes in Northwest Amazonia. Cambridge: Cambridge University Press; 1979.

17. Journet N. Lês jardins de paix. Etude des strutures sociales chez les Curripaco du haut Rio Negro (Comlombie). Paris: Museé de L'Homme; 1995.
18. Garnelo L, Buchillet D. Taxonomias das doenças entre os índios Baniwa e Dessano do Alto Rio $\mathrm{Ne}$ gro. Horiz antropol 2006; 26: 231-260.

19. Souza M LP, Garnelo L. Quando, como e o que se bebe: 0 processo de alcoolização entre populações indígenas do Alto Rio N egro, Brasil. Cad Saude Publica 2007; 23(7):1640-1648.

20. Hill JD. Myth and History. In: Hill JD, organizador. Rethinking history and myth: Indigenous South American perspectives of the past. Denver: University of Illinois Press; 1998. p. 1-34.

21. M inayo M CS. 0 desafio do conhecimento: Pesquisa qualitativa em saúde. $8^{a}$ ed. São Paulo: Hucitec; 2004.

22. Good BJ. M edicine, Rationality and Experience: an anthropological perspective. Cambridge: Cambridge University Press; 1994.

23. Ramirez H. A fala Tukano dos Ye'pâ-masa. Manaus: Centro "Iauaretê" de Documentação M issionária; 1997.

24. Lévi-Strauss C. Antropologia Estrutural Dois. 4a ed. Rio de Janeiro: Tempo Brasileiro; 1963.

25. Galvão WS, Galvão RC. Livro dos Antigos Desana Guahari Diputiro Porá. São Gabriel da Cachoeira: Federação das Organizações Indígenas do Rio $\mathrm{Ne}$ gro; 2004

26. Fernandes AC, Fernandes DM. A mitologia sagrada dos Desana-Wari Dihputiro Põrã. São Gabriel da Cachoeira: Federação das Organizações Indígenas do Rio Negro; 1996.

27. Lévi-Strauss C. The View from Afar. New York: Basic Books; 1985.

28. Wright RM. História indígena e do indigenismo no Alto Rio N egro. Campinas: M ercado de Letras; São Paulo: ISA; 2005. p. 83-107.

29. Viveiros de Castro E. A inconstância da alma selvagem. São Paulo: Cosac Naify; 2002. p. 87-180.

Artigo apresentado em 11/11/2009

Aprovado em 19/01/2010

Versão final apresentada em 25/01/2010 